\title{
A docência na Educação Infantil COM a Participação das Crianças
}

\section{Teaching in Early Childhood Education WITH Children's Participation \\ La docencia en la educación de la primera infancia CON la participación de los niños}

Katia Adair Agostinho*

\section{Resumo}

\begin{abstract}
A discussão aqui apresentada defende a docência na Educação Infantil com a participação das crianças. Considera que creches e pré-escolas ocupam um espaço fundamental na construção da democracia, quando fomentam relações democráticas nas práticas pedagógicas cotidianas como um modo de vida que insiste na (re)existência e persiste em tecer a vida coletiva e pública inscrita na ética do encontro em contraponto a exclusão. Em uma conjuntura em que a democracia se encontra em um descrédito abissal e a ofensiva aos direitos sociais incide fortemente nos mundos de vida das crianças, consideramos que a temática da educação democrática e da participação infantil ganha especial relevo e precisa de um debate profundo nas instituições de educação infantil, para que seus projetos educativo-pedagógicos e suas práticas sejam pensados à luz de referenciais críticos e inspiradores de novos modos de vida. Essa reflexão profunda terá de enfrentar nosso acanhado modo de sermos democráticos, em um país que não tem o legado de uma experiência efetivamente democrática e que se submete facilmente à sedutora forma de viver ditada pelo mercado, assim como o adultocentrismo existente nas relações pedagógicas; o que desnuda nossa frágil condição que precisa ser assumida por um pensamento rico, forte de contraposição ao que está posto.
\end{abstract}

Palavras-chave: Educação Infantil. Docência. Educação Democrática. Direitos. Participação das Crianças.

\section{Abstract}

The discussion presented here defends teaching in early childhood education with the participation of children. Believes that day care centers and preschools occupy a fundamental place in the construction of democracy, when they foster democratic relations in everyday pedagogical practices, as a way of life that insists on (re) existence and persists in weaving the collective and public life inscribed in the ethics of the encounter opposing the exclusion. At a juncture in which democracy finds itself in abyssal discredit and the offensive to social rights has a strong impact on the worlds of children, we consider that the theme of democratic education and child participation is particularly important and needs a deep debate on institutions of early childhood education, so that their educational-pedagogical projects and their practices are thought in the light of critical references and inspirers of new ways of life. This profound reflection will have to face our shy way of being democratic in a country that does not have the legacy of a truly democratic experience and which easily submits to the seductive way of life dictated by the market, as well as the adultocentrism that exists in pedagogical relations; This underscores our fragile condition that needs to be assumed by a rich thought, strong in opposition to what is set.

Keywords: Early Childhood Education. Teaching. Democratic Educacion. Rights. Children's Participation.

Recebido em 28/10/2019 - Aprovado em 30/01/2020

http://dx.doi.org/10.5335/rep.v27i2.11428

Doutora em Estudos da Criança, na Sociologia da Infância, Universidade do Minho/Portugal. Professora no Centro de Educação da Universidade Federal de Santa Catarina(CED/MEN/UFSC), Brasil. Orcid: https://orcid.org/0000-00030261-9790. E-mail:katia.ufsc@gmail.com 


\section{Resumen}

La discusión presentada aquí defiende la docencia en Educación Infantil con la participación de niños. Cree que las guarderías y preescolares ocupan un espacio fundamental en la construcción de la democracia, cuando fomentan las relaciones democráticas en las prácticas pedagógicas cotidianas como una forma de vida que insiste en la (re)existencia y persiste en tejer la vida colectiva y pública inscrita en la ética del encuentro en contraste con la exclusión. En una situación en la que la democracia está en desprestigio abismal y la ofensiva a los derechos sociales tiene un fuerte impacto en el mundo de los niños, consideramos que el tema de la educación democrática y la participación infantil adquiere especial importancia y necesita un debate profundo en las instituciones de educación infantil, para que sus proyectos y prácticas pedagógicas y educativas se piensen a la luz de referencias críticas y inspiren nuevas formas de vida. Esta profunda reflexión tendrá que enfrentar nuestra forma tímida de sermos democráticos, en un país que no tiene el legado de una experiencia efectivamente democrática y que se somete fácilmente a la seductora forma de vida dictada por el mercado, así como las relaciones pedagógicas centradas em el adulto; que exponen nuestra condición frágil que debe ser asumida por un pensamiento rico, fuerte en oposición a lo establecido.

Palabras clave: Educación de la primera infancia. Docencia. Educación Democrática. Derechos. Participación infantil.

\section{Adentrando a temática: urgência e obscurantismo}

A luz é sempre igual a uma outra luz. Depois se modificou: de luz se tornou alvorada incerta,

[...] e a esperança teve uma nova luz. P.P. Pasolini. A resistência e sua luz (1961)

A discussão que aqui propomos ganha contornos de acentuada urgência no quadro atual de nosso país e para além dele, tristemente! Um momento político social caracterizado por uma violência crescente, repressão de muitas ordens, imposição de um projeto civilizador de exclusão. O que torna nosso desafio mais complexo e vultoso diante do crescimento das desigualdades sociais e estruturais.

Clara está a dificuldade de prosseguir sem que antes possamos nos retirar de uma proposta de democracia nos moldes mercantilistas e à serviço da manutenção da ordem atual em que o capitalismo - financeirizado e neoliberal - leva seu projeto colonial às últimas consequências, sua realização globalitária. Em um contexto que se associa às forças conservadoras que ascendem ao poder gerando mais violência e barbárie (ROLNIK, 2018) em que reside muito obscurantismo e necessidade de ressemantização.

Mergulhar nos meandros dessa complexidade e nomear, pronunciar os aspectos dessa gramática de guerra e morte exige de nós um pensar/sentir/agir que detalhe e rememore o que fomenta tal ofensiva - tão forte e excessiva. É certo que alguns tempos são mais difíceis e incertos do que outros. Para nós, brasileiros, esses são tempos de profunda tristeza, estamos estarrecidos e (pre)ocupados com 
a velocidade com que muitas conquistas sociais e modos estabelecidos de ver questões sociais e educacionais são ameaçados e extintos, começam a desgastar-se, e ainda não somos capazes de dar respostas ou de fazer frente às forças do desmantelamento social. Como Peter Pal Pelbart, penso que - Estamos em guerra!

Guerra contra os pobres, contra os negros, contra as mulheres, contra os indígenas, contra os craqueiros, contra a esquerda, contra a cultura, contra a informação, contra o Brasil. A guerra é econômica, política, jurídica, militar, midiática. É uma guerra aberta, embora denegada; é uma guerra total, embora camuflada; é uma guerra sem trégua e sem regra, ilimitada, embora queiram nos fazer acreditar que tudo está sob a mais estrita e pacífica normalidade institucional, social, jurídica, econômica. Ou seja, ao lado da escalada generalizada da guerra total, uma operação que a abafa em escala nacional. Essa suposta normalização em curso, essa denegação, essa pacificação pela violência - eis o modo pelo qual um novo regime esquizofrênico parece querer instaurar sua lógica, em que guerra e paz se tornam sinônimos, assim como exceção e normalidade, golpe e governabilidade, neoliberalismo e guerra civil. Nada disso é possível sem uma corrosão da linguagem, sem uma perversão da enunciação, sem uma sistemática inversão do valor das palavras e do sentido do próprio discurso, cujo descrédito é gritante (PELBART, 2017a, sem paginação).

É nesse quadro de corrosão da linguagem, de perversão da enunciação, de inversão do valor das palavras e do sentido do discurso em que a democracia se encontra em um descrédito abissal em nosso país, que não tem o legado de uma experiência efetivamente democrática e que se submete, facilmente, ao sedutor modo de vida ditado pelo mercado. Essa guerra e ofensiva aos direitos incidem fortemente nos mundos de vida das crianças.

Embora o momento seja dramático, defendo, junto com outros, que não devemos nos submeter à imagem geral do desespero no sentido da desesperança, também devemos resistir ao clamor por uma derrota de entrega total. É necessário falar sobre nossas derrotas, mas não sucumbir a elas, é necessário aprender com elas, mas não cair na armadilha de discursos forjados que negam a política, a participação, a democracia, o que é público.

Em meio a um contexto tão sinistro não é bom deixar-se afundar no catastrofismo melancólico e derrotista, porque todo poder visa também a isto: nos separar de nossa força, nos inculcar a tristeza, a angústia, o medo, a culpa e sobretudo a sensação de impotência (PELBART, 2017a, sem paginação).

Se a cada dia parecemos mais vencidos, a derrota tem ao menos esta vantagem: ela nos força a pensar - e a pensar de outra maneira. É preciso fazer valer tal ocasião. [...] fazer do pensamento uma conspiração cotidiana, uma insurgência indomável (PELBART, 2017a, sem paginação).

Corroboro Stuart Hall quando afirma que os momentos de conturbação política produzem movimentos teóricos, no seu interesse pela teorização que emerge das 
lutas por transformação social, política e cultural, lutas concretas e contextuais que nos inspira a necessidade de "mobilizar tudo o que podemos encontrar em termos de recursos intelectuais para entender o que é que segue fazendo as vidas que vivemos e as sociedades em que vivemos, profundamente anti-humanas" (HALL, 1992, p. 17). É urgente pensar e construir outras lógicas, outros modos de vida e relacionamento, outros caminhos para a efetiva humanização sonhada.

Nesse contexto, como pensar/defender a democracia, as práticas democráticas na educação infantil, e para além dela, os direitos de participação das crianças? Como não naufragar com nossas ideias e palavras no mesmo continuísmo que alimenta a força e a voracidade do projeto neoliberal e conservador que nos assola?

O momento nos exige o esforço de pensamento crítico e criação, com atenção constante e intensa à gramática que utilizamos para poder dizer, mais próximo e melhor, da tessitura/urdidura complexa da docência nesta etapa educacional. Enfrentemos com coragem a tarefa de democratizar a educação, aprofundando e enriquecendo a democracia.

\section{Re(existir) acentuando as relações democráticas nas práticas pedagógicas}

Traçamos um caminho de pensamento, no qual uma forma de fazer frente a tudo isto é a de pensar a educação em um lugar distinto do dominante, dando atenção ao mundo e nele reconhecer a vida (SKLIAR, 2017), contrapondo-se às lógicas de mercado, consumo desenfreado e destrutivo, ranking e sua concorrência, meritocracia, estandardização do pensamento, racismo, sexismo, xenofobia, intolerância, ódio etc, que elege insistir no público, no bem comum, na política, na coletividade.

Carlos Skliar colabora com nosso desafio de traçar caminhos possíveis de (re) existir com sua perspectiva de que "la detención sería la única rebelión posible frente a un mundo que no te deja descansar," nos contrapondo à ideia da aceleração, com uma ação pedagógica cotidiana que possa fomentar uma nova forma de fazer política e elaborar novos rumos para pensar e construir a afirmação da vida, da infância, que possa liberar as crianças do mundo do mercado. Este é "el único propósito que la educación puede tener, si aún nos queda algo de dignidad y de alteridad" (SKLIAR, 2017).

Aunque sueñe extraño hoy día: enseñar es enseñar a contra-tiempo. Hay un mundo mucho más largo y más ancho para mostrar: el del juego, la lectura, el pensamiento, la filosofía, la música, la escritura, la pintura, los cuerpos, la historia de los hombres y las mujeres, la literatura, la danza de los números, la danza sin los números, la geografía de las travesías, 
la realidad de los sueños, la memoria de los ancianos, el lenguaje de la infancia. Enseñar la detención, la pereza, la desatención, la lentitud, el tiempo libre liberado del mercado, la distracción, el titubeo, la fragilidad (SKLIAR, 2017, s.p.).

A defesa é a de acentuar, adensar, fomentar, fortalecer práticas pedagógicas democráticas nas creches e pré-escolas, assim como em todas as instituições de ensino - universidades, escolas, para que sejam espaços de resistência em tempos de ataques à democracia, onde possamos pensar e efetivar alternativas democráticas construídas coletivamente, tendo em atenção que não devemos pensar a mesma isoladamente das reais condições de realização da escolarização nas atuais circunstâncias da vida das nações e mundo. Estamos diante hoje de uma "batalha cultural" pelos sentidos das relações sociais mais amplas e da vida escolar, em particular. Para tanto,

Es necesario entonces volver a ligar la relación entre la infancia y la política, en el sentido de la acción y la praxis, y desplazar la preponderancia de las retóricas prolijas sobre los derechos de la infancia que no alteran los núcleos duros de la reproducción de la desigualdad. [...] la educación desde edades tempranas representa una deuda de la sociedad y del Estado para llegar justo a tiempo y también una apuesta por las nuevas generaciones en términos de una batalla cultural central (REDONDO, 2015, p. 157).

A conquista dos direitos das crianças - Constituição Federal (1988), Convenção dos Direitos das Crianças (1989), Estatuto da Criança e do Adolescente (1990) -, fruto das lutas sociais de diferentes atores e, da produção teórica de abordagens inclusivas em uma perspectiva de inclusão geracional, aproxima os campos da política e da infância por meio do reconhecimento da criança como cidadã. Possuir direitos é uma das características de ser cidadão, e a partir disso as crianças devem ser consideradas cidadãs embora provavelmente não exerçam sua cidadania da mesma forma que os adultos (JANS, 2004; LISTER, 2007). Assim, a defesa de uma educação infantil com a participação das crianças é fulcral para a produção e consolidação de uma sociedade de afirmação de direitos sociais, como espaços de educação democráticos que se contraponham à exclusão social.

As crianças como sujeitos de direitos e de conhecimento são produtoras de sentido e têm "voz", são legítimas as formas de comunicação e relação que utilizam para expressar seu ponto de vista. Ao fazê-lo, contribuem na renovação e reprodução dos contextos em que participam quando existe quem esteja interessado em ouvir suas vozes. Aqui incide com muita força as nossas concepções sobre criança e infância. 
Consideramos a criança como ator social, a infância como construção socio-histórica e a vivencia dos direitos negociada nas relações que são travadas junto aos seus sujeitos em uma perspectiva de direito à infância. Em um quadro de pedagogias contra-hegemônicas, que favoreça e fomente práticas pedagógicas em que as crianças sejam tidas em conta e seu ponto de vista seja considerado na estruturação de seus espaços e tempos educativos.

A Pedagogia da Infância, balizada num projeto emancipatório, com uma concepção de criança como sujeito de direitos e ator social, afirma a imprescindibilidade de considerarmos seu ponto de vista, expressado por diferentes canais comunicacionais, para a organização e efetivação das práticas pedagógicas, o que exige uma tomada de posição referente à participação infantil nos contextos de sua educação.

A discussão a respeito da participação das crianças para uma educação democrática se cruza com um conjunto de conceitos importantes que precisam ser aprofundados, compreendidos e conectados pelo coletivo das unidades educativas, para que seja possível contar com as contribuições delas na efetivação da educação aqui preconizada, para assim vencer modelos adultocêntricos.

Com esse princípio, as creches e pré-escolas - como lugar de prática ética e política, de cidadania, de democracia - organizam e efetivam sua docência com intencionalidade democrática participativa, fomentando tempos e espaços para a participação de todos os sujeitos envolvidos: crianças, familiares, todos os profissionais e comunidade. Intencionalmente abre espaço-tempo para o Outro, no exercício diário de construir a vida coletiva da docência.

Compreendendo que a intencionalidade pedagógica nas práticas se tece sabendo-se que ninguém pode antecipar a potência de um encontro, cada contexto terá suas particularidades no modo de construir sua efetiva vivência, tendo em vista as materialidades e subjetividades que constituem cada experiência localizada nas diferentes categorias sociais, de modo que o significado de criança sujeito de direitos são negociados em contexto, para enfrentarmos os riscos de sua reificação (LLOBET, 2011).

A docência, por se constituir de maneira relacional, nos coloca a presença do Outro. Mesmo quando esse reconhecimento não ocorre, o Outro sempre está ali e sua presença incide nas relações pedagógicas que se travam no convício diário da jornada educativa. Jorge Ramos do Ó contribui para seguirmos neste aprofundamento dos meandros constitutivos da docência que aqui preconizamos com sua 
ideia de um pedagogo em andamento, que convoca a tarefa instante da intencionalidade pedagógica, sendo aquela

[...] que se recusou com a maior verticalidade ética a vestir a pele do transmissor, do divulgador, do comentador da obra alheia. De cada vez que se nos dirigem nessa condição de professores-investigadores, é invariavelmente para nos mostrar, por meio de seu exemplo e testemunho, como esse ofício ou posição pode ser ocupado por uma ideia preparada e refletida, mas que está sempre a recomeçar ali mesmo no espaço da sala de aula uma pesquisa que se desenvolve como um vento forte: que nos pode mostrar a adjunção, o desmembramento ou até mesmo a desagregação de uma ideia, de um conceito, de uma paisagem empírica, mas que não se faz compreender imediatamente, deixando-nos impactados bem para lá do momento da sua passagem. Seja de que ângulo for, deparamo-nos sempre com uma prática da interrogação que atinge não apenas a matriz da palavra, quanto a sua organização, mutação e até comunicação pública $(O ́, 2019$, p. 4, grifos nosso).

Aqui descortina-se que assumimos como projeto educativo-pedagógico essa prática sistemática e intensa de pensamento e interrogação, que acolhe o acontecimento como elemento que nos mobiliza à transformação, como

[...] algo que não pode ser programado, irrupção imprevista: o começo de nova narrativa, de uma nova compreensão, de uma nova relação com o mundo. $\mathrm{O}$ acontecimento é, também, uma determinada experiência de vivência do tempo. Isto significa, então, que o acontecimento só se explica como uma ocasião, como um estado de exceção, como o imprevisível, como um instante original, como aquilo que quebra por surpresa e racha a continuidade do tempo. E o impacto do acontecimento só pode estar nessa relação inédita que nós estabelecemos com esse fato ou com o que esse fato produz e provoca em nós. A experiência que dali nasce transforma o fato em acontecimento significativo e assume, então, a forma de uma relação de interesse pessoal. E nos interessa particularmente essa ideia de interesse pessoal, esse "dar-se conta", que é como uma chave para pensar fertilmente o campo educativo. "Dar-se conta - diz Jankélévitch - é descobrir sem mover do lugar a velha novidade [...] mas, completamente renovada pela maneira de percebê-la $(1989$, p. 161 apud SKLIAR, 2009, p. 42).

Por isso é fundamental um projeto de educação que reivindica a experiência na Educação Infantil, como potência na transformação da realidade contemporânea vivida pela humanidade (JANUÁRIO, 2018). A experiência como antidoto para o apesar de tudo com seu acento na memória e narrativa. Com esta base, temos alguns aspectos que são importantes de serem salientados e que podem favorecer e sustentar a participação infantil, compondo um caminho possível para a construção da educação democrática aqui defendida. 


\section{Desdobramentos no cotidiano das creches e pré-escolas}

A temática da participação das crianças é profunda e complexa, exige atenção em seus desdobramentos e enfrentamentos cotidianos na efetivação da docência, exige perseguir os modos de sua tradutibilidade. Concordo com Peter Moss (2009) de que um dos primeiros passos para que essa prática democrática se instaure é assumir a opção por este direcionamento com intencionalidade política e pedagógica, o que exige pensar, refletir e discutir coletivamente nas unidades educativas: queremos mesmo a democracia, o que ela significa para nós, como exercitá-la nas práticas cotidianas? Como pensamos os direitos de participação das crianças? É esta a posição e defesa da unidade?

É fundamental que as pré-escolas e creches, assim como os sistemas que as apoiam, pensem, reflitam o que a democracia pode significar nos contextos de educação infantil (DAHLBERG; MOSS, 2005; MOSS, 2009; BAE, 2009, AGOSTINHO, 2010), evitando visões irrefletidas sobre ela. Essa é uma tarefa que nos coloca a importância de pensar e discutir os projetos político pedagógicos, em documentos e ações, das unidades: temos pensado-refletido e discutido em nossas creches e pré-escolas a temática? Qual a nossa posição? Quais estratégias elegemos para efetivá-la?

Isto dá relevo à importância de uma formação sólida e crítica em nível inicial para todas as professoras e professores dessa etapa educacional, demandando espaço nos currículos dos cursos de Pedagogia às discussões acerca dos direitos das crianças e, em especial, os de participação. Esta demanda também se coloca para a formação continuada e em serviço.

A opção por um projeto educativo pedagógico democrático e emancipador requer professoras e professores críticos, para que com sensibilidade, astúcia e perspicácia possam compreender as diferentes formas pelas quais as crianças expressam seus pensamentos e sentimentos, apreender a complexidade da participação das crianças em suas rotinas educativas, sua multidimensionalidade, e, tendo em vista nosso reconhecimento da inteireza humana, construir estratégias comunicativas de ausculta.

Explicita-se assim a importância da docência na educação infantil intencional e cotidianamente disposta a apreender o conteúdo expressado-comunicado pelas crianças sobre seus pontos de vista, acolhendo-os na estruturação e organização do cotidiano educativo, com abordagens e práticas pedagógicas que apoiem os fins da educação democrática, a ética do cuidado e do encontro e uma atitude de inclusão 
das diferenças e construção do bem comum, atento a práticas autoritárias e adultocêntricas, neoliberais e neoconservadoras, que enfraquecem a democracia, em um pleno exercício de compartilhamento de poder, com vistas à construção da vida em comum.

Consideramos que as relações democráticas são processos criados pelos participantes, algo vivido. A participação não é dada, ao contrário, é um processo que envolve interação, expressão de ideias, pensamentos, opiniões, escolhas, negociações em uma perspectiva dialógica da política. Com atenção aos aspectos não linguísticos da comunicação, ao reconhecimento da diferença, da pluralidade, e à valorização da emoção e da sensibilidade.

As formas próprias e preferidas das crianças de expressar opiniões precisam ser melhor compreendidas e traduzidas para que se efetivem os processos de participação na docência. Estudos como o de Jans (2004), Bae (2009), Landsdown (2010), Agostinho (2010), entre outros, indicam algumas formas pelas quais as crianças comunicam e expressam seus pontos de vista, seus sentimentos e opiniões, com destaque para:

- o corpo, com seus movimentos, gestos e expressões;

- os afetos exprimidos e estendidos entre elas mesmas e entre elas e os adultos;

- o humor como forma de explicitar e viver a alegria e interrogar a vida com um pensamento questionador de certezas absolutas;

- as culturas de pares - com ênfase nas brincadeiras - como constituidora de sua identidade geracional.

O corpo, os afetos, o humor, enfim as culturas de pares são ricas formas de participação das crianças que exigem atenção contínua e intencional às suas manifestações para apreendermos os conteúdos expressados-comunicados por elas, realizando a (re)invenção de uma democracia ao alcance das crianças de 0 a 6 anos, a cidadania vivida nas creches e pré-escolas em que vivem sua infância.

Praticada na relação social, a participação das crianças na docência precisa manter especial atenção no risco da reprodução de modelos adultocêntricos, considerando-se as especificidades das crianças pequenas, suas diferenças e diversidades. Os encaminhamentos pedagógicos precisam cuidar para que não incorram nos deslizes comuns de que assembleias, eleições e escolhas são suficientes para o pleno reconhecimento da contribuição geracional. É necessário que sejamos cuidadosos ao incluir as estruturas formais de participação com as crianças, pois é improvável que possam acolher a diversidade de vozes infantis. Esses modelos costumam gerar 
relações hierárquicas e tendem a legitimar uma relação de poder desigual, projetados de forma unilateral por adultos, podem silenciar as crianças, nos desafiando a pensar e efetivar abordagens alternativas à participação das crianças na esfera pública, em que é necessário acolher uma grande diversidade de vozes infantis.

A propagada máxima de que ouvir as vozes das crianças seria as deixar falar também precisa ser, cuidadosamente, revista, embora reconheçamos que nem isto se tenha ainda conquistado plenamente em muitos âmbitos. O que queremos realçar aqui são os modos próprios das crianças pequenas que interrogam e tencionam a reprodução de modelos que nem sempre atendem às suas especificidades e necessitam de tempos diversos para acolher suas manifestações.

A participação se constrói no tempo, se aprende e se refina, comporta um exercício e capacidade de observação e de escuta. Por isso uma das estratégias que julgamos fulcral é a ausculta, imprescindível para o desenvolvimento de abordagens em que a cultura de comunicação comece a partir da posição da criança, e que se reconheçam as suas diferenças, a fim de que possamos construir práticas democráticas estabelecidas no paradigma da escuta, implicadas na comunicação humana.

[...] o termo ausculta não é apenas uma mera percepção auditiva nem simples recepção da informação - envolve a compreensão da comunicação feita pelo outro. Inclui a recepção e compreensão, que, principalmente neste caso - o da escuta da criança por adulto sempre passará por uma interpretação. Tal análise da expressão oral do outro/ criança orienta-se pelas próprias intenções colocadas nessa relação comunicativa - lembrando que, quando o outro é uma criança, a linguagem oral não é central nem única, mas fortemente acompanhada de outras expressões corporais, gestuais e faciais (ROCHA, 2008, p. 45).

A observação e escuta atentas aos modos próprios como as crianças comunicam seu ponto de vista exigem um conjunto de conhecimentos e sensibilidade acerca delas para apreender todos os conteúdos expressos pelos seus diversos canais comunicacionais. Essas estratégias destacadas, de observação e escuta/ausculta, são acompanhadas por uma prática de registro e documentação pedagógica, em que documentamos e partilhamos os pontos de vista das crianças com o coletivo que vivencia a unidade. A documentação pedagógica, assim, apoia a participação das crianças.

Ao reconhecer o papel ativo das crianças na construção da vida social, temos de ter em atenção os diferentes ritmos, tempos e formas de sua participação. É necessária, assim, uma lógica organizacional pedagógica que se abre para a comunicação e o intercâmbio, com o tempo necessário para a escuta, que fomente com equilíbrio diferentes modos de encontro, diálogo, negociação, com espaços e tempos plurais, em que sejam possíveis grupos menores e maiores para que as ideias de 
todos tenham lugar, para que possam ser expostas, ouvidas, debatidas, negociadas. Com igualdade de acesso para todos na vida em grupo, vida coletiva, com garantia de visibilidade e expressão de diferentes racionalidades, em que se exercitam o respeito pelo outro, proporcionando o confronto entre pontos de vista.

A educação como um lugar onde se dá e tem tempo! Aquela que se contrapõem ao tempo linear e se abre para a experiência e o acontecimento, como caminho para ativações mobilizadoras e transformadoras, sacode e desestabiliza a raiz da acelerada e sedutora trama enredadora do mercado, com sua incapacidade de presença, acento no individualismo e sua insaciável privatização e acumulação. Essa educação fomenta práticas de cooperação democrática em todos os domínios e, assim, fecundamente nos aproxima do que de fato nos faz viver - a preservação da vida estabelecida sob o princípio do comum.

A ação docente nessa direção expande o tempo, provê e apoia oportunidades de debate, negociação e estruturação coletiva da jornada diária, criando outros espaços, outros tempos para a expansão da potência, do possível e necessário encontro, da partilha da vida comum, contrapondo-se à crise de presença com e na vida a nossa volta. A presença posiciona-se contra a passividade e submissão, nos inscreve como cidadãos que se ocupam com o que nos diz respeito.

Tal perspectiva exige a contraposição em relação às formas de vida instituídas para o mercado, contraria o assujeitamento, a submissão da subjetividade, fortalecendo a capacidade de pensar outras maneiras de viver, novas formas de (re) existência, inventadas nos encontros de experimentação de novos modos de existências, com novas formas de cooperação, de sensibilidade, de percepção, de relação com o tempo, com o corpo, com a infância, com os sonhos (PELBART, 2017b).

Assim propomos re(existir) acentuando as relações participativas nas práticas pedagógicas inclusivas de todos os sujeitos envolvidos, intensificadoras da diferença, pensando a educação pública na contramão da comercialização da vida! Com pensamentos e palavras como "lampejo e a esperança intermitentes dos vaga-lumes. Lampejo para fazer livremente aparecerem palavras quando as palavras parecem prisioneiras de uma situação sem saída" (DIDI-HUBERMAN, 2011, p. 130).

\section{Finalizar para abrir 0 debate}

Nessa batalha cultural, compreendida como uma resistência necessária, somos capazes de nas relações educativo-pedagógicas cotidianas nas creches e pré-escolas potencializá-las como lócus democráticos? Lugar de participação com vistas 
ao bem comum? Espaço-tempo-lugar em que o projeto educativo-pedagógico vise novas formas de sociabilidade, de composição e partilha da vida?

As possibilidades de ação no sentido aqui defendido em um contexto tão difícil e desfavorável, nos convoca a criar, reunindo forças próximas e realizando mudanças locais, considerando as creches e pré-escolas como espaços privilegiados de construção democrática da vida coletiva pública. A participação das crianças menores nos espaços educativos pode ser uma força, uma importante contribuição da geração que chega, especialmente, se estivermos em busca de construir outros modos de convívio, mais comprometidos com o bem comum, com o que é público.

A radical centralidade na vida coletiva, em que todos nos inscrevemos, nos convoca para a mudança nos padrões de sociabilidade e consumo das sociedades ditas desenvolvidas, sendo a redistribuição dos recursos pela população do planeta base para a democracia. Contemporaneamente, o ataque à democracia nos impõe a tarefa de fomentar o diálogo democrático e o debate público. As instituições de educação infantil como local que acolhe a infância tem uma forte possibilidade de instaurar relações em que a vida coletiva conta com a contribuição de todos os envolvidos, exercitando a cidadania desde a tenra idade.

Ocupar as creches e pré-escolas experimentando novas formas de organização, de auto-organização, de sociabilidade, de produção de uma vida outra, convoca outros espaços, outros tempos, outra subjetividade, porque esta que aí está interrompe, impossibilita o bem comum, o bem viver. Assim, pensar possibilidades de resistir a este momento difícil no Brasil e no mundo, no âmbito educacional e em tantos outros, instaurando processos educativos-pedagógicos coletivos estabelecidos - de praticar e pensar, portanto, de criar - nos leva a encontrar caminhos de transformação mesmo diante de tantas adversidades.

A docência com a participação das crianças constrói um projeto democrático e emancipador. Sendo as instituições de educação infantil contextos de socialização política das crianças, onde elas exercitam e vivenciam sua cidadania na vida coletiva e individual nos processos de decisão, nas relações de poder diversas, influenciando, transformando e/ou mantendo a estrutura organizacional cotidiana. Defendemos, assim, que tempos e espaços educativos-pedagógicos constroem em sua cotidianidade um tempo de direitos, estruturando suas jornadas com o efetivo contributo das crianças nas negociações e decisões coletivas organizadoras da estrutura institucional.

Com isso, afirmamos a "voz" das crianças, que têm opiniões, ideias, experiências e sentimentos a nos dizer, assegurando sua expressão pelos diferentes canais 
comunicacionais, assumindo como legítimas as suas formas de comunicação e relação na renovação e reforço dos laços sociais nos espaços em que participam. Assim, atentamos aos aspectos não linguísticos da comunicação, à ética do cuidado e da solidariedade para com o Outro, ao reconhecimento da diferença, à preservação da pluralidade, à valorização da emoção e da sensibilidade, fortalecendo e reinventando a construção da democracia com a docência na Educação Infantil COM a participação das crianças.

\section{Referências}

AGOSTINHO, Kátia Adair. Formas de participação das crianças na Educação Infantil. 2010. Tese de Doutorado em Estudos da Criança. (Especialização em Sociologia da Infância). Instituto de Educação, Universidade do Minho, Portugal, 2010.

BAE, Berit. Children's right to participate - challenges in everyday interactions. In: European Early Childhood Education Research Journal. v. 17, n. 3, p. 391-406, 2009.

BRASIL. Constituição da República Federativa do Brasil: promulgada em 5 de outubro de 1988. Contém as emendas constitucionais posteriores. Brasília, DF: Senado, 1988.

BRASIL. Decreto n. 99.710, de 21 de novembro de 1990 b. Promulga a Convenção sobre os Direitos da Criança. Disponível em: http://www.planalto.gov.br/ccivil_03/decreto/1990-1994/ D99710.htm. Acesso em: 5 mar. 1991.

DAHLBERG, Gunilla. \& MOSS, Peter. Ethics and politics in early childhood education. London: Routledge Falmer, 2005.

DIDI-HUBERMAN, Georges. Sobrevivência dos vaga-Iumes. Tradução: Vera Casa Nova e Márcia Arbex. Revisão: Consuelo Salomé, Belo Horizonte: Editora UFMG, 2011.

HALL, Stuart.Race, Culture, and Communications: Looking backward and forward at Cultural Studies. In: Rethinking Marxism, 5, p. 10-18. 1992.

JANUÁRIO, Cristiane. "Pintou? Agora chega! É a vez do amiguinho!” A Educação Infantil reivindica a experiência. 2018. Dissertação (Mestrado em Educação) Programa de Pós-Graduação em Educação, Universidade Federal de Santa Catarina, 2018.

JANS, Marc. Children as Citizens: towards a contemporary notion of child participation. In: Childhood, v. 11, n. 1, p. 27-44, 2004.

LANDSDOWN, Gerison. The realisation of children's participation rights. In: PERCY-SMITH, Barry; THOMAS, Nigel. A Handbook of Children and Young People's Participation. Perspectives from theory and practice. London: Routledge, p. 11-23, 2010.

LISTER, Ruth. Why citizenship: where, when and how children? In: Theoretical Inquiries in Law, v. 8, n. 2, p. 692-718, 2007. 
LLOBET, Valéria. Las políticas para la infancia y el enfoque de los derechos en América Latina. Algunas reflexiones sobre su abordaje teórico. In: Fractal: Revista de Psicología Niteroi: Universidade Federal Fluminense. Col. 23 n. 3, p. 447-469, septiembre-diciembre, 2011. Disponível em: http://www.uff.br/periodicoshumanas/index.php/Fractal/issue/view/177/showToc Acesso em: 25 ago. 2017.

MOSS, Peter. Introduzindo a política na creche: a educação infantil como prática democrática. In: Psicologia - USP, São Paulo, julho/setembro, v. 20 n.3, 417- 436, 2009. Disponível em: http:// www.scielo.br/scielo.php?script=sci_arttext\&pid=S0103-65642009000300007. Acesso em: 12 jan. 2010.

Ó, Jorge Ramos do. Ouvir falar o pensamento, aprender a falar o pensamento no interior da universidade: o testemunho dos "professores" Michel Certeau, Gilles Deleuze, Michel Foucault e Roland Barthes. Revista Brasileira de. Educação [on-line]. v. 24, 2019. Disponível em: http:// www.scielo.br/scielo.php?script=sci_arttext\&pid=S1413-24782019000100217. Acesso em: 28 jun. 2019.

PELBART, Peter Pal. Estamos em guerra. Cordéis Político Pandemia. São Paulo: N-1 edições, 2017a.

PELBART, Peter Pal. Mutações contemporâneas. PUC/Minas, 2017b. Disponível em: https:// www.youtube.com/watch?v=CvZgWntWu3g\&t=2751s. Acesso em: 11 fev. 2018.

REDONDO, Patrícia. Infancia(s) Latinoamericana(s), entre lo social y lo educativo. In: Espacios en Blanco - Serie indagaciones - № 25 - Junio, p. 153-172, 2015. Disponível em: https:// pt.scribd.com/document/316406570/Infancia-s-Latinoamericana-s-entre-lo-social-y-lo-educativo-Patricia-Redondo. Acesso em: 12 ago. 2017.

ROCHA, E. A. C. 30 anos da Educação Infantil na Anped: Caminhos da Pesquisa. 30ª In: Zero a Seis, Florianópolis, v. 10, n. 17, jan./jun, 52-65, 2008. Disponível em: https://periodicos.ufsc.br/ index.php/zeroseis/article/view/1980-4512.2008n17p52/6082. Acesso em: 13 ago. 2008.

ROLNIK, Suely. O novo tipo de golpe de estado: um seriado em três temporadas. In: $E l$ Pais,12 MAI 2018. Disponível em: https://brasil.elpais.com/brasil/2018/05/12/actualidad/1526080535_988288.html. Acesso em: 12 maio 2008.

SKLIAR, Carlos. Entrevista a Carlos Skliar: Hay que volver a una escuela de la inutilidade. $L a$ Voz. Disponível em: http://www.lavoz.com.ar/ciudadanos/entrevista-carlos-skliar-hay-que-volver-una-escuela-de-la-inutilidad. Acesso em: 12 ago. 2017.

SKLIAR, Carlos. La educación (que es) del outro: notas acerca del desierto argumentativo en educación. Antioquia: Separata, 2009. 